\title{
Evguêni Oniêguin: em busca de um estilo
}

\author{
Alipio Correia de Franca Neto e Elena Vássina
}

\begin{abstract}
Resumo: Apresentamos a tradução das primeiras dez estrofes do Capitulo I do romance em versos Evguêni Oniêguin, de Aleksandr Púchkin (1799-1837), que contou também com a colaboração inestimável do falecido Prof. Boris Schnaiderman. No artigo ressaltamos preferências de abordagens teóricas que acabaram por influenciar as "escolhas" da tradução, em termos de uma tentativa de reconstituição de estilo desta obra fundamental da literatura russa.
\end{abstract}

Palavras-chaves: A. Púchkin; romance Evguêni Oniêguin; traducão.

Já faz muito tempo que o estilo deixou de ser considerado apenas em termos de seus traços linguísticos. Questões como outridade, contextualização, aspectos psicológicos, estrangeirização, modos específicos e culturalmente limitados de conceitualizar e exprimir sentidos, a par de modos universais de fazê-lo vieram a fazer parte do estudo do estilo. Para Jakobson, por exemplo, o estilo era o que definia a diferença entre textos literários e não literários.

Ele estava particularmente interessado em características que pudessem fazer de textos obras literárias. $\mathrm{Na}$ verdade, tinha isso em comum com adeptos da Nova Crítica Americana, como Cleanth Brooks, por exemplo, e proponentes ingleses da close reading, como I. A. Richards e William Empson. Desse ângulo, tal interesse dá a razão da predileção de Jakobson por poesia. A seus olhos, ela parecia lhe encarnar a natureza essencial da literatura, em virtude do nexo que apresentava - passível de observação -, entre forma e conteúdo. Ao afirmar que

1 Pós-doutor em Teorias da Tradução e Doutor em Teoria Literária e Literatura Comparada pela Universidade de São Paulo. E-mail: alipiofranca@ig.com.br

2 Profa. Dra. DLO/FFLCH/USP. E-mail: elenavassina@usp.br 
toda língua se vale dos mesmos recursos, Jakobson considerava a linguagem literária e, em particular, a poética, uma modalidade com um funcionamento diferente, visto que ela fazia um uso distinto dessas mesmas fontes - um uso responsável pela "função poética". Segundo suas famosas verbalizações, essa função "projeta o princípio de equivalência do eixo de seleção sobre o eixo de combinação". Bradford (1994. p. 13), interpretando as ideias de Jakobson, acreditava que um denominador comum em sua obra era que "a substância material do signo nunca é inteiramente distinguível de suas propriedades significantes". Desse ângulo, ao se transpor o signo de uma língua para outra, suas "propriedades significantes" seriam diferentes.

É de notar que esses argumentos implicavam a ideia da perda da unidade entre forma e conteúdo, e, claro, a impossibilidade de "tradução". É muito comum se esquecer, porém, que esses mesmos argumentos acabariam sendo relativizados num artigo de 1959, em que ele afirmava que a tradução de poesia não poderia se dar senão por meio de "transposição criativa". Na verdade, a explicação dessa afirmação foi dada por ele por meio de uma menção, a propósito de um obstáculo poético", a São Constantino, que "opõe resolutamente o preceito de Dionísio, o Aeropagita, segundo o qual deve-se estar atento aos valores cognitivos..., e não às palavras propriamente ditas":

Se fosse preciso traduzir para o português a fórmula tradicional "traduttore, traditore" por "o tradutor é um traidor", privaríamos o epigrama rimado italiano de um pouco do seu valor paronomástico. Donde uma atitude cognitiva que nos obrigaria a mudar esse aforismo numa proposição mais explícita e a responder a perguntas: tradutor de que mensagem? Traidor de que valores? (JAKOBSON, 1970, p. 72)

Como se vê, as preocupações de Jakobson iam além dos aspectos formais da poesia, e, a exemplo de Richards e outros, ele considerava metáforas, metonímias e outras figuras de linguagem como decorrentes de processos psicológicos. Com isso, haveria de antecipar de modo pioneiro a Estilística Cognitiva ${ }^{3}$. De qualquer forma, a exploração dos "valores cognitivos" da linguagem aludidos por Jakobson - os quais, diferentemente dos argumentos que enfatizam a unidade entre forma

3 O que não deixa de ser um fato curioso, já que sua própria linguística é de base indutiva e estruturalista, e, diferentemente da Estilística Cognitiva, não tem a mente humana como foco principal de suas preocupações. 
e sentido na poesia, eram "traduzíveis" - punham em relevo as relações entre os elementos universais e culturalmente específicos nas línguas, ou o que Levine, por exemplo, chamou de "vínculos secretos entre todas as línguas" (LEVINE, 1991, p. 8), que tornariam possível a "tradução"

$\mathrm{O}$ interesse de Jakobson pelo universal subjazendo ao específico, manifesto em títulos de ensaios como "A Magia de uma Linguagem Comum", ou "À Procura da Essência da Linguagem", também estava por trás de suas famosas descrições de tipos de traduções (intralingual, intersemiótica e interlingual), que traziam implícita a ideia de que diferentes modos de transposição, como reescrita ou adaptação, poderiam ser considerados "traduções".

$\mathrm{Na}$ época em que Jakobson começava a escrever sua obra, a linguística estruturalista não estava apta a explicar essas coisas. Seu foco principal eram regularidades, ou características comuns, por trás de detalhes de línguas específicas. Só quando a linguística porém passou a se ocupar dos "valores cognitivos" de Jakobson, tornou-se possível explicar aquelas características comuns como consequência da estrutura da mente.

Preocupações de ordem pragmática e psicológica, bem como a preocupação quanto a contextos culturais, considerados agora como construtos cognitivos, assimilando aspectos sociais e históricos da produção e da compreensão dos textos, viriam assim a ser conciliadas em análises derivadas da Linguística Cognitiva, com sua crença na ideia de uma relação de universalidade com a escolba individual no estilo. Desse ângulo, pelo simples fato de uma escolha estilística ser sempre opcional, o estilo nos diz algo sobre a pessoa que usa a expressão.

Esses e outros aspectos contextuais, pois, acabaram por se integrar aos estudos estilísticos, cada vez mais preocupados com suas origens na mente do escritor e seus efeitos sobre a mente do leitor. Assim, o contexto, no sentido de plano de fundo, passou a ser considerado por sua vez como "uma entidade psicológica". A conclusão disso é que, ao tentar reconstituir um estilo numa tradução, o tradutor não faz senão reconstituir "valores cognitivos identificados por ele no texto, sempre atentando para a especificidade de estados mentais sob a influência de sociedades / culturas diversas. Desse ponto de vista, sua própria “leitura” do estilo de um texto

4 É verdade que essas argumentações foram motivo de suspeição da parte de autores sobretudo com orientação pós-estruturalista ou pós-modernista, que enfatizaram o que Assman (ASSMANN, 1996:, p. 85) chamou, como dissemos, de "fundamentalização da pluralidade", para ele uma forma de respeitar a outridade na tradução. No entanto, como tantas vezes se disse, não há nada errado com o universalismo per se, contanto que ele venha acompanhado de a uma consciência de possíveis limitações. 
é o que lhe fornece o inventário do que a professora Jean-Boasse Beier chama de "cerceamentos" que ele precisará superar em seu trabalho de escrita".

É fácil perceber que a percepção crítica que um tradutor tem de diversos estilos literários exerce seu efeito sobre suas traduções, em que cada palavra advirá de uma escolha (em oposição àqueles aspectos da língua que não se prestam a opção), baseada por sua vez em sua compreensão pessoal de traços estilísticos identificáveis no original, estes também servindo de base para o leitor/crítico de tradução interpretar o que o tradutor fez.

No espaço limitado de um artigo, essas reduções um tanto violentas acerca de tópicos tão abrangentes visam apenas a ressaltar preferências em termos de abordagens teóricas que acabaram por influenciar as "escolhas", em termos de uma tentativa de reconstituição de estilo, em nossa tradução do Evguêni Oniêguin (1823-1831), de Aleksandr Púchkin (1799-1837), que contou também com a colaboração inestimável do falecido Prof. Boris Schnaiderman e a ser publicada em breve pela Ateliê Editorial.

Chamado de "enciclopédia da vida russa” pelo crítico Vissárion Belínski, esse "romance em versos" representa para a literatura da Rússia o mesmo que os Lusíadas, A Divina Comédia, o Dom Quixote e as peças de Shakespeare representam respectivamente para Portugal, a Itália, a Espanha e a Inglaterra.

Aleksandr Púchkin é o mais universal dos poetas russos. Fiódor Dostoiévski chegou a dizer que sua obra era uma afirmação da ideia da universalidade da Rússia, e que o sentimento de compaixão destilado em sua obra legitimava o parentesco autêntico do seu gênio com os gênios de todos os tempos e povos do mundo. Ao mesmo tempo, de modo paradoxal, "Puchkin representa uma extraordinária manifestação, talvez a única, do espirito russo", como bem apontou outro escritor russo célebre, Nikolai Gógol. Já durante quase dois séculos Púchkin representa o maior ícone cultural da Rússia. Ele é considerado o fundador da literatura russa moderna, suas obras fazem parte das leituras obrigatórias dos russos e seu nome está presente em toda parte da Rússia.

Evguêni Onéguin é um romance escrito em versos tetrâmetros (mais ou menos equivalentes aos versos de oito sílabas em português), num total de 384 estrofes de 14 versos cada. Trata-se, pois, de uma obra que realiza uma verdadeira fusão de modalidades literárias - romance e poesia -, fusão que curiosamente lhe empresta um sabor na época do pós-modernismo, que é também, dentre outras

5 Uma edição de ensaios críticos de sua autoria, organizada e traduzida por Correia Neto, será lançada em breve pela Ateliê Editorial. 
coisas, a era da narratividade. Em termos de linguagem, a obra é a expressão máxima do gênio de Púchkin, cuja magia reside sobretudo em sua naturalidade de expressão, capaz de fazer com que as palavras mais comuns, utilizadas por nós em conversas, se encham de conteúdo poético e ironia. Em virtude dessa fluência verbal, os versos de Evguêni Onéguin acabam criando uma impressão de absoluta espontaneidade e leveza.

Ora, falar dessa "impressão de absoluta espontaneidade e leveza" é falar de um "estilo" original, e as estrofes que se seguem, como uma amostra do livro, não poderiam ser senão resultado da "intenção" dos tradutores de o reconstituir tão mimeticamente ${ }^{6}$ quanto possível a cada escolha, e de sua crença em "equivalências" - essa ilusão necessária - que possam ser reconhecidas pelo leitor.

\section{Capítulo I}

E corre para viver e se apressa a sentir.

\section{Príncipe Viázemski ${ }^{7}$}

«Мой АяАя самых честных правиц,

Когда не в шутку занемог,

Он уважать себя заставиц

И кучше выдумать не мог.

Его пример Аругим наука;

Но, боже мой, какая скука

С больным силеть и день и ночь,

Не отходя ни шагу прочь!

Какое низкое коварство

Полуживого забавцять,

Ему поАушки поправ ять,
Meu tio dos mais nobres preceitos,

Quando ficou doente à beça,

Logrou dos outros o respeito,

Sem invenção melhor do que essa.

O exemplo sirva de lição;

Mas, meu bom Deus!, que amolação,

Passar com um morto-vivo hora a hora,

Sem nunca pôr o pé pra fora!

Que insídia reles e que tédio,

Ter que entretê-lo o tempo inteiro,

Lhe endireitar o travesseiro,

6 Concepções e conceitos mencionados aqui, como o de "paráfrase poética" são desenvolvidos em CerzidoInvisivel: Regras de um Jogo, de Correia Neto, a ser lançado pela Ateliê Editorial.

7 A epígrafe é extraída de "A Primeira Neve" (1819), poema do príncipe Piotr Viázemski (1792-1878), um amigo íntimo de Púchkin mencionado diversas vezes no Oniêguin e aparecendo em pessoa no Capítulo VIII. O sujeito da oração é o "ardor juvenil" comparado à excitação de uma corrida de trenó. 
Печально подносить мекарство,

Вздыхать и думать про себя:

КогАа же черт возьмет тебя!»

II

Так думац молодой повеса,

Аетя в пыли на почтовых,

Всевышней волею Зевеса

Наследник всех своих родных.

Арузья Аюдмилы и Руслана!

С героем моего романа

Без преАисловий, сей же час

Позвольте познакомить вас:

Онегин, Аобрый мой приятель,

Родился на брегах Невы,

ГАе, может быть, родились вы

Или блистали, мой читатель;

Там некогда гулял и я:

Но вреден север Аля меня.

III

Служив отлично благородно,

Аолгами жиц его отец,

Аавац три бала ежегодно

И промотался наконец.

Судьба Евгения хранила:
Com aspecto triste, dar remédio

E com um suspiro, se indagar,

"Quando o diabo vai-te levar?”

II

Pensava assim o nosso boêmio,

Num coche ${ }^{8}$ voando pela poeira,

Por decisão de Zeus supremo

Herdeiro da família inteira.

Leitor de Ludmila e Ruslam?!

Vou apresentar a todo fã

O meu herói, e com um relato

Sem preâmbulos e de imediato:

Meu amigo, Oniêguin, foi nascido

Próximo às margens do Nievá ${ }^{10}$,

Talvez tenha nascido lá,

Brilhado lá, leitor querido;

Também passeei nesse local:

E a mim o Norte ${ }^{11}$ me fez mal.

III

Após servir exímio e lhano,

O pai só emprestava dinheiro,

Dava três bailes todo ano

E torrou o patrimônio inteiro.

A sorte guarda Evguêni Oniêguin:

8 No original, literalmente, "carruagem de posta".

9 Ruslan e Ludmila (1820), um poema pseudo-épico, foi a primeira grande obra de Púchkin a granjear popularidade, e embora tenha suscitado o estranhamento dos críticos quando de sua publicação, sobretudo em virtude de uma surpreendente mistura de gêneros e estilos, ela acabaria por consagrar Púchkin como um dos escritores mais notáveis e promissores da época.

10 Rio que atravessa todo o centro de São Petersburgo.

11 Alusão ao primeiro exílio de Púchkin ao sul do Império russo em 1820, ocorrido devido ao fato de poemas políticos de Púchkin terem sido considerados subversivos. Reza a nota I de Púchkin ao capítulo: "Escrito na Bessarábia". 
Сперва Madame за ним ходила, Потом Monsieur eе сменил.

Ребенок был резов, но мил.

Monsieur l'Abbé, француз убогой,

Чтоб не измучилось Аитя,

Учиц его всему шутя,

Не Аокучал моралью строгой,

Слегка за шалости бранил

И в Аетний саА гулять водил.

IV

КогАа же юности мятежной

Пришла Евгению пора,

Пора надежА и грусти нежной,

Monsieur прогнали со Авора.

Вот мой Онегин на свободе;

Острижен по последней моде,

Как dandy мондонский одет -

И наконец увидел свет.

Он по-французски совершенно

Мог изъясняться и писаА;

\егко мазурку танцевац

И кланялся непринужАенно;

Чего ж вам больше? Свет решил,

Что он умен и очень мил.

V

Мы все учились понемногу

Чему-нибудь и как-нибудь,
Para Madame ${ }^{12}$ foi entregue,

Então Monsieur a substituiu.

Infante inquieto, mas gentil.

Monsieur l'Abbé, pobre francês,

Pra não afadigar a criança,

Em tudo a instruía com folgança,

Sem regras chatas, sisudez;

Birras causavam sua revolta

E a guiava ao Liétni Sad ${ }^{13}$ pra volta.

IV

Tendo a estação da rebeldia

Advindo a Evguêni certa hora,

De esperança e melancolia,

Monsieur foi posto porta afora.

Eis meu Oniêguin solto, ei-lo,

Seguindo a moda no cabelo,

Trajado de dandy londrino -

E no fim viu o mundo grã-fino.

Falado ou escrito, o seu francês

Era impecável ${ }^{14}$; se dançasse

Mazurca, o passo tinha classe;

Saudava de um jeito cortês;

Que queres mais? O mundo viu

Que tinha brilho e era gentil.

V

A gente estuda um pouco disso,

Daquilo e seja como for;

12 Os refugiados da Revolução francesa de 1789 na Rússia em geral eram empregados como tutores pelas famílias aristocráticas russas.

13 O Liétni Sad [literalmente, "Jardim de Verão"] é um parque criado pelo imperador Pedro, o Grande, no centro de São Petersburgo à beira do rio Nievá que na época de Púchkin se tornou um lugar para os passeios matinais de crianças.

14 Saber falar e escrever em francês impecável era uma exigência da aristocracia russa do século XIX, por isso, o francês era a primeira língua que se ensinava aos filhos das famílias nobres. 
Так воспитаньем, слава богу,

У нас немудрено блеснуть.

Онегин был по мненью многих

(Судей решительных и строгих)

Ученый малый, но педант:

Имел он счастливый талант

Без принужАенья в разговоре

Коснуться до всего слегка,

С ученым видом знатока

Хранить молчанье в важном споре

И возбужАать улыбку Аам

Огнем нежАанных эпиграмм.

VI

\атынь из моды вышла ныне:

Так, если правду вам сказать,

Он знац довольно по-латыне,

Чтоб эпиграфы разбирать,

Потолковать об Ювенале,

В конце письма поставить vale,

$\triangle$ а помник, хоть не без греха,

Из Энеиды два стиха.

Он рыться не имел охоты

В хронологической пыли

Бытописания земли:

Но Аней минувших анекдоты
Daí, bom Deus, não ser difícil,

Em nosso meio, o esplendor;

A muitos, nosso Oniêguin era

(Aos de opinião firme e severa)

Alguém versado, mas pedante:

Tinha o talento cativante

De resvalar qualquer matéria

Com jeito, tudo sendo dito

Com uns ares doutos de perito;

Calava-se em conversa séria,

Fazia as damas rir com as chamas

De inusitados epigramas ${ }^{15}$.

VI

Latim saiu de moda agora:

Mas, vou dizer-lhe uma verdade,

Sabia bem latim - embora

Pra ler epígrafes ${ }^{16}$, tratar de

Um poeta como Juvenal ${ }^{17}$, e,

Ao concluir cartas, pôr um vale ${ }^{18}$,

Lembrando uns dois versos completos

Da Eneida ${ }^{19}$, embora não corretos.

De historiografias terrestres

Não desejava revolver a

Cronologia e sua poeira;

Mas anedotas dos ancestres,

15 Púchkin usa "epigrama” não como definição do gênero poético (saberemos que Oniêguin não possui nenhum dom poético), mas como um comentário sarcástico.

16 A palavra epígrafe é usada aqui no sentido original do termo grego (epigrafhé), qual seja, inscrição em prosa ou verso talhada sobre tumbas ou em outros lugares em honra a pessoas e eventos na Grécia antiga.

17 Juvenal (c. 42-c.125 d. C.) foi um poeta romano satírico, bastante popular entre os decembristas em virtude das denúncias que fez de despotismo e corrupção.

18 Forma epistolar latina no arremate de uma carta.

19 Poema épico de Vergílio (70-19 a. C.). 
От Ромула до наших дней

Хранил он в памяти своей.

VII

Высокой страсти не имея

А^я звуков жизни не щадить,

Не мог он ямба от хорея,

Как мы ни бились, отличить.

Бранил Гомера, Феокрита;

Зато читал ААама Смита

И быц глубокой эконом,

То есть умел судить о том,

Как государство богатеет,

И чем живет, и почему

Не нужно золота ему,

КогАа простой продукт имеет.

Отец понять его не мог

И земли отАавац в залог.

VIII

Всего, что знал еще Евгений,

Пересказать мне недосуг;

Но в чем он истинный был гений,
Dos dias de Rômulo até agora,

Ele guardava na memória.

\section{VII}

Sem o alto afã de sacrifício

Em prol de sons, troqueus e jambos,

Por mais esforços nossos pra isso,

Ele não distinguia entre ambos;

Homero $^{20}$ e Teócrito ${ }^{21}$, chatice,

Mas lia em troca Adam Smith ${ }^{22}$

E era um economista e tanto,

Isto é, avaliava quanto

Faz rico o Estado, do que vive,

Por que motivo, quando tem

Produto simples ${ }^{23}$, o ouro vem

A ser de fato prescindível.

Seu próprio pai não o compreendia

E hipotecou-lhe a terra um dia.

VIII

O mais que conhecia Evguêni

Falta ocasião pra que o relate;

Mas no que ele era mesmo um gênio,

20 Antigo poeta grego, a quem se atribui a autoria da Ilíada e da Odisséia.

21 Antigo poeta grego, autor de célebres idílios, que floresceu no terceiro século antes de Cristo. Iúri Lotman lembra que os pré-românticos russos, à procura de uma cultura nacional e popular contraposta à precedente tendência elitista e ocidental do rococó, traduziram extensamente Homero e Teócrito e neles se inspiraram.

22 Economista escocês (1723-1790) que influenciou bastante as ideias político-econômicas dos membros da conspiração dos dezembristas - revolucionários da alta nobreza russa que participaram da revolta contra a coroação do czar Nicolau I em 14 de dezembro de 1825. Embora Púchkin não fosse um participante direto desse movimento revolucionário, ele tinha vários amigos próximos entre dezembristas.

23 Um dogma fundamental da teoria econômica fisiocrata, que se originou na França do século XVIII, de acordo com o qual a riqueza se baseava no "produit net" da agricultura. O interesse pela economia política foi um traço característico da juventude russa no período de $1818-1820$. 
Что знац он тверже всех наук,

Что было Аля него измлада

И труА, и мука, и отрада,

Что занимало целый день

Его тоскующую Аень, -

Была наука страсти нежной,

Которую воспем Назон,

За что страАальцем кончиц он

Свой век блестящий и мятежный

В Молдавии, в глуши степей,

ВАали Италии своей

IX

$\mathrm{X}$

Как рано мог он мицемерить,

Таить надежду, ревновать,

Разуверять, заставить верить,

Казаться мрачным, изнывать,

ЯвАяться гордым и послушным,

Внимательным иль равнодушным!

Как томно был он молчалив,
O que sabia mais do que à arte,

O que lhe fora desde o início

Batente, júbilo, suplício

E o que ocupava cada instante

De sua indolência angustiante

Era a arte da paixão airosa

Que $\mathrm{Naso}^{24}$ decantou em loas,

Por que sofreu, e então findou a

Sua era ilustre e tempestuosa

$\mathrm{Na}$ Moldávia, na estepe densa,

Longe da Itália de nascença.

$\mathrm{IX}^{25}$

$\mathrm{X}$

Quão cedo soube usar disfarce,

Velar o anseio, mostrar ciúme,

Levar a crer, desenganar, se

Mostrar soturno, com azedume,

Com ar de altivez e obediência,

Ou de atenção e indiferença!

Quão langoroso silenciava,

24 Trata-se do poeta romano Públio Ovídio Naso (43 a. C.-16 d. C.), autor das Metamorfoses e do escandaloso poema erótico $A$ Arte de Amar, com quem Púchkin sentia ter certa afinidade em virtude de seu exílio: Ovídio morreu em exílio junto ao Mar Negro. Diga-se que a alusão à $A$ Arte de Amar de Ovídio acrescenta uma nuança pejorativa ao caráter das aventuras amorosas de Evguêni.

25 Na edição de Evguêni Oniêgui, Púchkin omitiu esta estrofe, indicando a omissão com três linhas pontilhadas. Diga-se aliás que, ao longo do poema, as estrofes omitidas são de três tipos; as escritas e descartadas; as que Púchkin intentava escrever mas nunca levou a cabo; e as vazadas num estilo irônico a modo de Sterne, Byron e Hoffmann. O importante é que as estrofes omitidas deveriam ser compreendidas não como uma "lacuna" do texto, mas como pausas semânticas com o efeito estético de sugerir, como ressaltou o célebre teórico do formalismo russo, Iúri Tyniánov, que o romance que se lê extrapola a representação dessas mesmas estrofes. 
Как пламенно красноречив,

В сердечных письмах как небрежен!

ОАним Аыша, оАно Аюбя,

Как он умел забыть себя!

Как взор его был быстр и нежен,

СтыАлив и Аерзок, а порой

БАистал послушною слезой!
Quão inflamada a sua palavra,

Nas cartas de amor, que descaso!

Respirando, amando um objeto,

Como esquecia de si! Que inquieto

E terno, tímido e audaz o

Olhar, que às vezes de repente

Luzia com a lágrima obediente!

\section{Referências}

BRADFORD, M. Roman Jakobson: Life, Language and Art. Londres Londone Nova New York, Routledge, 1994.

JAKOBSON, R. Linguística e Comunicação. São Paulo, Cultrix, 1970.

LEVINE, S. J. The Subversive. Minnesota, Graywolf Press, 1991.

ASSMANN, A. "The Curse and Blessing of Babel: or looking back on universalisms". in "The

Translatability of Cultures: figurations of the space between", Sanford Budick e Wolgang Iser (orgs.), Stanford University Press, 1996. 